\title{
Determination of a Section of Woji Riverbed Depths for Safe Navigation
}

\author{
Ekpa, A.U. ${ }^{1, *}$ and Eyakndue, N.I. ${ }^{1}$ \\ ${ }^{1}$ Department of Geoinformatics and Surveying, University of Uyo, Uyo, Nigeria \\ Corresponding Author:*akwaowoekpa@uniuyo.edu.ng
}

\begin{abstract}
The depths of the oceans, seas, rivers, etc. and charting the shape and topography of the ocean floor are only determined though bathymetric processes. And mariners primarily depend on water depths beneath their vessels for safe navigation. Bathymetry also goes a long way to enhance the identification of possible features on the seabed such as elevation changes, rock outcrop, wreckages, sunken vessels, pipeline, or any other obstructions that could cause hazard to navigation. This study employs the bathymetric principles to determine river-bed depths of a section of the Woji River for the purpose of creating a two-dimensional view of the underlying sub-surface and a threedimensional model of the river-bed, to enhance safe navigation. Data acquisition was done using satellite imagery from Google Earth, total tide prediction data, sounding depths using Midas echo sounder and GPS data. Data processing performed on observed bathymetric data include spike removal, tidal correction on instantaneous depths. The processed depths were analysed and presented in form of profile view, graphs, and charts. A flow and sedimentation simulation was carried out using ArcGIS 10.3, to show the nature of the river. The tidal data aided in sounding reduction, and river average depth of $6.022 \mathrm{~m}$ was obtained. The levelling mis-closure was $0.001 \mathrm{~m}$ and the average variation in echo sounder calibration was $0.08 \mathrm{~m}$. Based on the acquired and output data, the produced chart revealed sedimentation effect on the convex coastline, uneven riverbed topography possibly due to sand excavation, which could pose serious danger to the safety of navigation. Based on these results, the use of Sub-Bottom Profiler and a Multi-Beam Echo Sounder (MBES) is therefore recommended in order to improve the quality of data obtained.
\end{abstract}

Keywords: Bathymetry, chart, tidal data, navigation, mariners, accuracy, sedimentation

\subsection{Introduction}

Seafloor mapping is one of the oldest profession known to humankind. Mariners have been measuring the depths under their vessels for thousands of years, primarily for safe navigation. Striking the rocky ocean floor would imperil the ship, threaten loss of life, and jeopardize the livelihood of those aboard. As time passed, charts derived from seafloor mapping took on a decidedly military purpose for naval warfare and were kept as closely guarded national secrets. Today, national governments, militaries, telecommunication companies, petroleum corporations, and academic institutions map the seafloor for many applications. Also, fishing activities need detailed chart in order to avoid loss of fishing gear and fishing vessels to undetected or poorly identified obstructions. They also need it to identify fishing areas where fishing is limited or prohibited (Spratt, 1989). Knowledge about our benthic habitat and seafloor is imperative as we go forward to better understand the oceans and the Earth, as this is achievable through bathymetry.

Bathymetry is the science of measuring the depths of the oceans, seas, etc. and charting the shape and topography of the ocean floor (Panigrahi, 2014). Bathymetry goes a long way to enhance the identification of possible features on the seabed such as elevation changes, rock outcrop, wreckages, sunken vessels (where any exist), pipeline, or any other obstructions that could cause hazard to navigators. Recently, the instruments universally employed for this type of survey are the conventional echo sounders and swath sounding system. 
The process of a bathymetric survey is dependent on three important observables:

i. positional accuracy - the location of survey vessels and other surface and sub-surface structures during marine operations (Ojinnaka, 2007);

ii. accuracy of tidal data - the vertical measurement of water level fluctuation at the time of survey (Breman, 2010). Normally obtained at tidal station established near the survey area either automatically or manually, and;

iii. depth measurement - the use of single beam or multi beam echo sounder to determine depth.

It is a known fact that the inhabitants of Woji community in Rivers State have witnessed the loss of lives and property on the Woji River. Most of these wrecks were as a result of vessels that ran aground particularly during the period of low tide and due to lack of knowledge about the feature below them. It was also noticed that the dune of the river was gently eroded. The number of vessels (about 10-15 vessels daily) sailing through this route to a nearby vessel dock revealed that there was dire need for efficient bathymetric chart to aid in traffic monitoring and management.

The aim of this study was to employ the principles of bathymetric survey to determine river-bed depths of a section of the Woji River for the purpose of creating a two-dimensional view (contour lines) of the underlying sub-surface and a three-dimensional (raster) model of the river-bed, to enhance safe navigation. The specific objectives to achieve this aim were: to measure water depths, determine sounding points, observe tides and delineate the coastline; to describe all objects that are conspicuous and prominent to the mariners; to show a profile view of the sea bed which is important during excavation of seabed sand for land reclamation purposes; and to create a 3D model of the riverbed, and produce a Bathymetric Chart.

\subsection{Study Area}

The Woji Creek is an estuarine tidal water, located between Latitudes $04^{\circ} 48^{\prime} 25.34^{\prime \prime} \mathrm{N}$ and $04^{\circ} 48^{\prime} 46.20^{\prime \prime} \mathrm{N}$, Longitudes $07^{\circ} 03^{\prime} 40.53^{\prime \prime} \mathrm{E}$ and $07^{\circ} 03^{\prime} 01.37^{\prime \prime} \mathrm{E}$, stretching over a distance of about 1.5 kilometres. It is a tributary of the Upper Bonny Estuary in Port Harcourt, Rivers State in the Niger Delta Region of Nigeria (Figure 1). The dominant vegetation is Nypa Palm (Nypa function) and white (Avecennia). Nypa Palm is becoming a resilient plant in the location. The river passes through many communities including Oginigba, Woji, Azubiae, Okrika. Many human activities take place on, within and around this Creek such as fishing, boating and disposal of human waste. Based on the surrounding activities, the river receives effluent discharges from many industries, residential buildings and the main Port Harcourt abattoir sited along the bank.

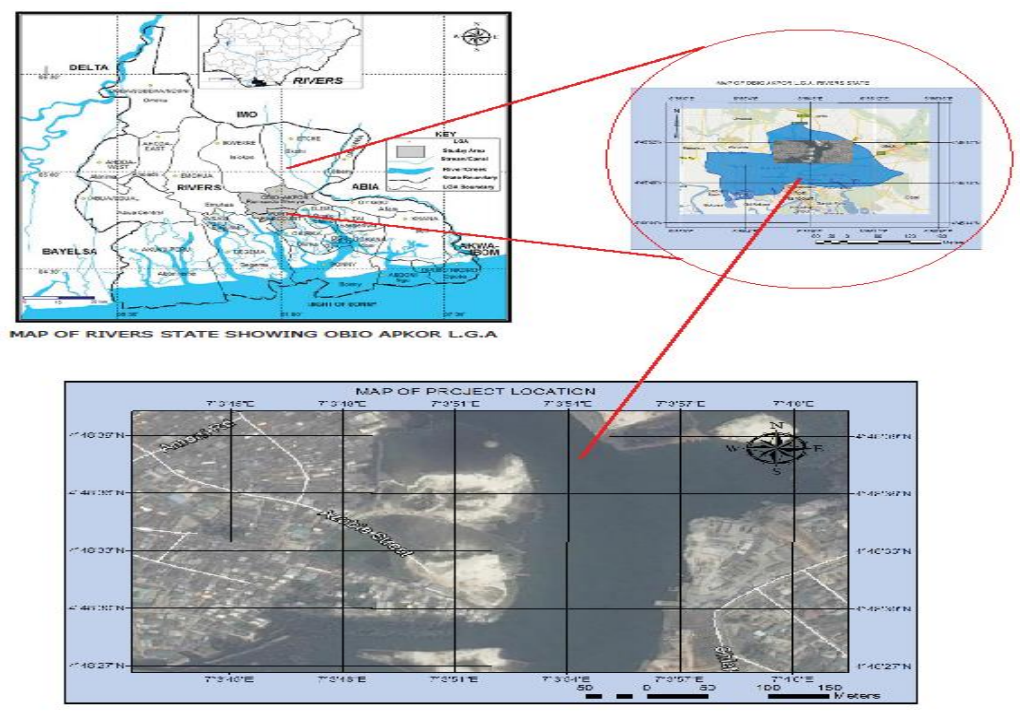

Figure 1: Map of the Study Area 


\subsection{Methodology}

The processes involved in this study were reconnaissance, control establishment, data acquisition, data processing, data analysis, and presentation. A flow chart showing the adopted systematic approach is as shown in Figure 2.

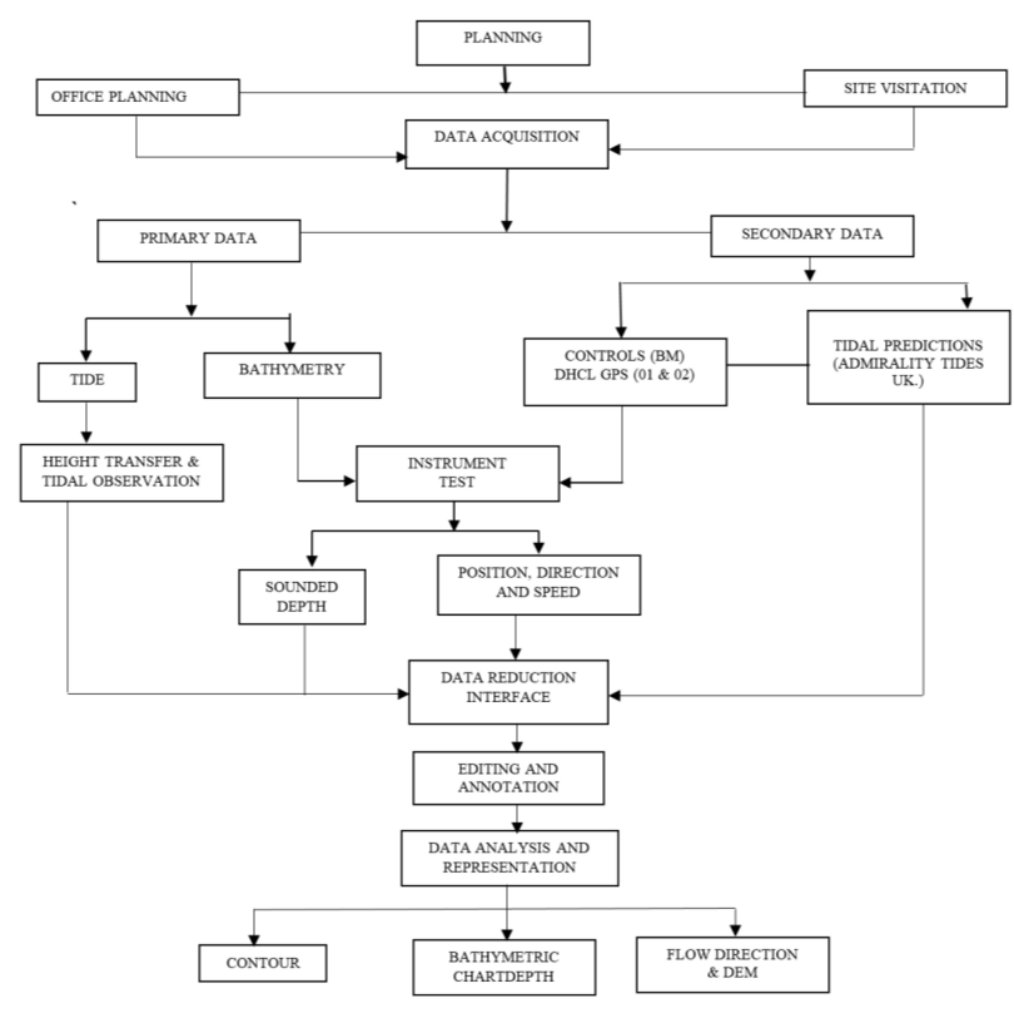

Figure 2: Flowchart of Methodology

\subsection{Planning}

The basic components considered during the planning stage are as enumerated below:

i. $\quad$ Exact area of the survey;

ii. Type of survey, scale;

iii. Scope of the survey (short or long term).

iv. Platforms available (ships, launches, aircraft, leased vessels, cooperative agreements).

v. Support work required (aerial or satellite photography, geodetics, tides).

vi. Limiting factors (budget, politics, geographic or operational constraints, positioning system limitation, and logistics).

Other important information available in the survey area also reviewed. They included sound velocity information, climatology, water clarity data, past survey data, and information from light lists, sailing directions, and notices to mariners. Tide gauge location was chosen and local vertical control data checked to ensure expected accuracy standards so that the tide gauges could be linked to the vertical datum. Sounding line spacing, the total miles of survey track and time required for the survey were computed. Sounding lines were laid out so that there will be no gaps.

\subsection{Reconnaissance}

The process involved control identification, mapping out possible leveling route and locating a good spot for tide gauge establishment. The available controls located are shown in Table 1. 
Table 1: Existing Control Points (Source: Digital Horizon Company Ltd.)

\begin{tabular}{|l|l|l|l|}
\hline Station & Eastings & Northings & Heights \\
\hline GPS 01 & $285036.185 \mathrm{~m}$ & $532359.501 \mathrm{~m}$ & $4.844 \mathrm{~m}$ \\
\hline GPS 02 & $285118.509 \mathrm{~m}$ & $531942.445 \mathrm{~m}$ & $4.953 \mathrm{~m}$ \\
\hline
\end{tabular}

\subsection{Design of Sounding Lines}

AutoCAD Civil3D 2016 was used to design the sounding lines as represented in Figure 3. The intervals were $25 \mathrm{~m}$ at cross sections and designed to run perpendicular to the contour and parallel to each other according to IHO standard.

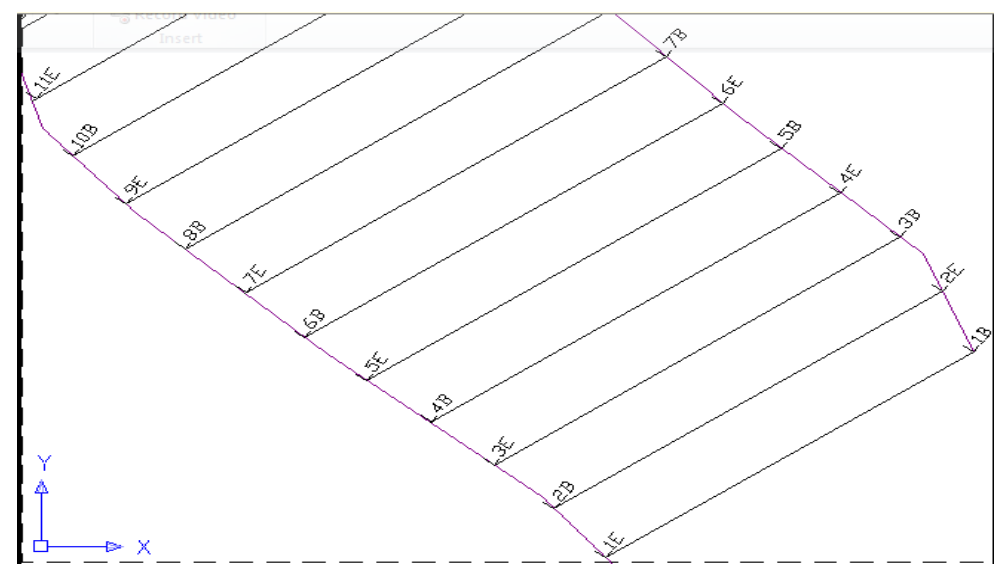

Figure 3: Design of Sounding Lines

\subsection{Instrumentation}

The equipment (hardware and software) employed to carry out this study included Midas Surveyor Echo sounder (with accessories), GPS receiver, Kolida automatic level, automatic tide gauge, survey log, Google Earth Imagery, AutoCAD Civil3D 2016, Surfer 12. and ArcGIS 10.3.

The hard wares were checked for calibrations before being used to acquire data. For instance, the level's line of collimation was checked using the two-peg test method to determine if it is truly horizontal so as to know the correction factor to be applied (See Figure 4).

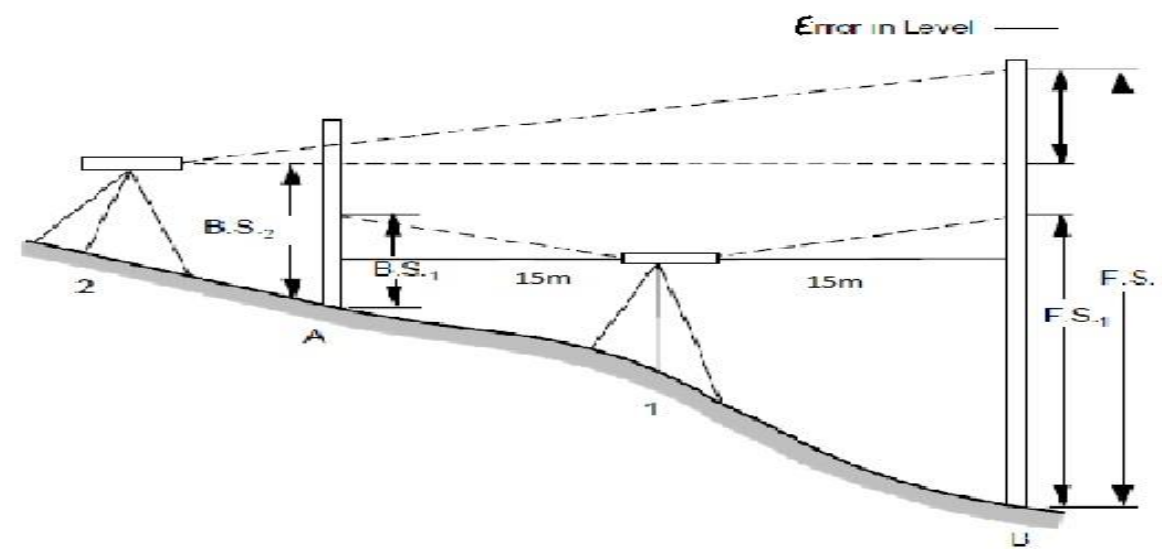

Figure 4: Two Peg Test for an Automatic Level

On reduction of the data, it was found out that the difference between the Back-Sight and Fore-Sight readings for the first instrument station $($ Points $) 1$ was: $\mathrm{BS}-\mathrm{FS}=(1.445-1.297)=0.148$. 
And the difference between the Back-Sight and Fore-Sight readings for the second instrument station at (Point 2) was: $\mathrm{BS}-\mathrm{FS}=(1.495-1.342)=0.153$.

The difference between the two results was given as: $0.153-0.148=0.0005$

Collimation error is given by $e=\frac{\text { Difference between height difference }}{\text { Distance between the two staff stations }}$

$$
e=(0.153-0.148) / 30=0.00016 \mathrm{~m} \text {. }
$$

Hence, correction applied $=(1.495-0.00016 * 30)=1.4902$ metres .

\subsection{Data Acquisition}

The following under listed data set were acquired for this study:
a. Height Transfer data
b. Tidal readings (Predicted Tide values from Total Tide)
c. Sounded Depth values
d. Positioning values
e. Google Earth Imagery of Woji Community year 2015.

\subsubsection{Height Transfer}

This was carried out using differential levelling technique to relate the water level to a known benchmark, and the height of water at a particular time $(8: 20 \mathrm{am})$ to the tidal value obtained from the tide gauge.

\subsubsection{Determination of Tidal Values}

Water level readings were obtained from the installed tide gauge to nearest millimetre at interval of 10 minutes as illustrated in Figure 5. However, the tidal values obtained were not used as it was not sufficient to deduce the mean low water and the mean high water, which would be used for reduction of the sounding depths. Instead tidal prediction values were obtained from Total Tide prediction and used for the soundings depths reduction.

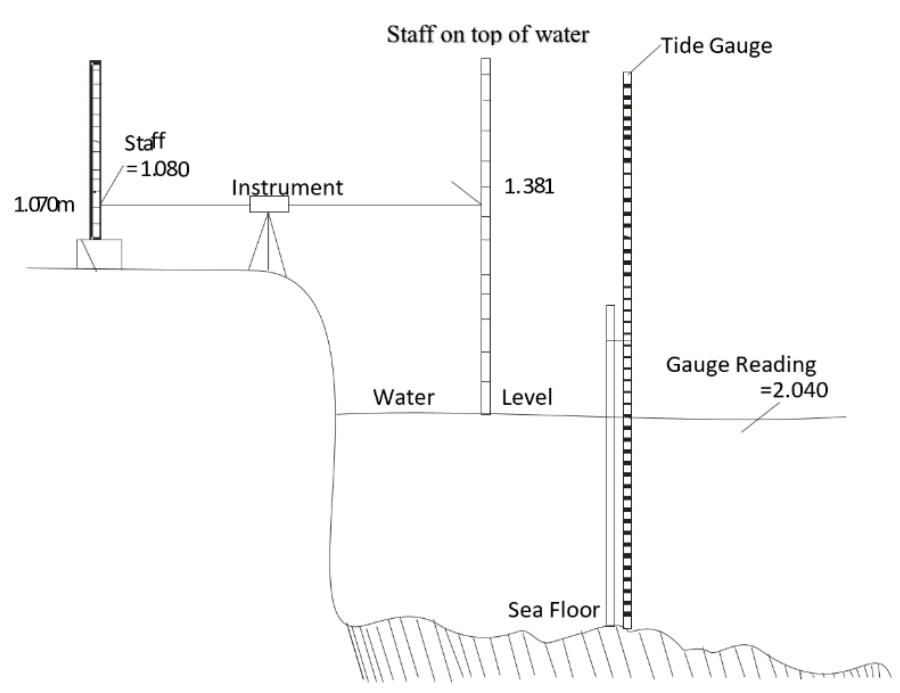

Figure 5: Diagram of Tide Gauge Installation and Levelling of water surface

\subsubsection{Bar Check Calibration}

Calibration of the Echo sounder used, is as important as testing any land survey equipment for inherent errors and its precision. This is done to maintain consistency in depth pinged. As the acoustic wave travels through the water medium, it is affected by speed, salinity, temperature and pressure of the water (Ojinnaka, 2007). This either slows the wave or increases the wave from the transducer to the seabed 
and its return signal. Hence, the need for Bar Check calibration. This process was performed before and after the sounding operation as described in the Figure 6.

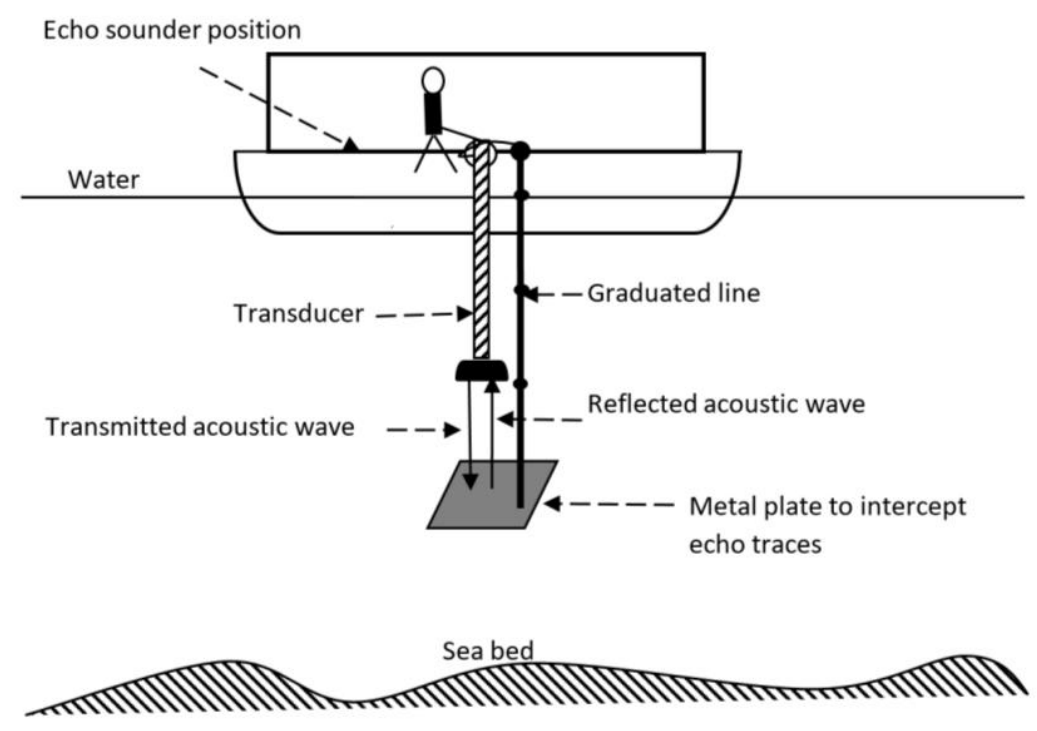

Figure 6: Echo sounder Calibration by Bar Check method (Source: Ojinnaka, 2007)

\subsubsection{Depth Determination}

A Midas Dual Frequency Echo Sounder was used to carry out the sounding operation. The Echo sounder was set up inside the vessel, while its transducer and GPS antenna were both fixed at the side of the vessel ensuring that the GPS was directly overhead the transducer. The draft of the transducer was read and keyed into the system as $0.3 \mathrm{~m}$. All ellipsoidal, time/date, frequency, velocity, and zone parameters were keyed into the system.

The automated method (time-based pinging method) was employed to determine depths as the vessel travels along the designed sounding lines. For each second the echo sounder returns 6 pings (depth). A graph of the depth is displayed on the screen in Figure 7. This process continued along the run lines, except for obstacles and for areas that were shallow or silted.

A considerable large volume of data to clean, as this data most either will be reduced to one ping per second, or one ping per five seconds, depending on the volume of data the operator can handle. For this project the data was reduced to one depth per 5 seconds.

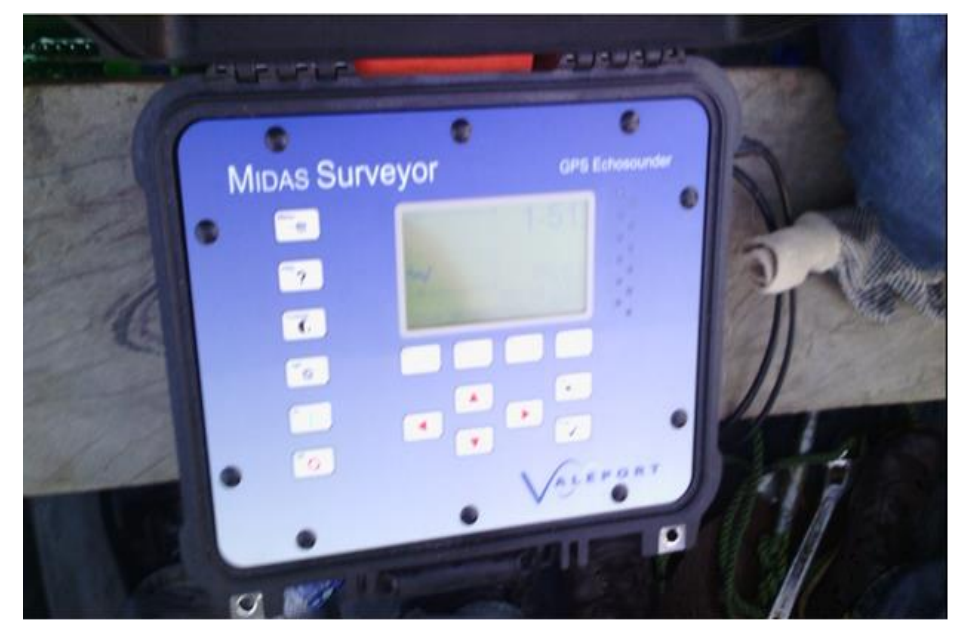

Figure 7: Midas GPS Echo sounder 


\subsubsection{Horizontal Positioning}

The horizontal datum employed for this work was the World Geodetic System (WGS 84). The Midas Echo Sounder is configured with a dual frequency GPS receiver just for the instrument. This receiver cable is connected to the Echo Sounder. Once connection is established, the coordinates and speed of the vessel is displayed, as the speed is a function of the position of the vessel at every given time, computed from the coordinates obtained. The coordinates obtained were absolute.

\subsubsection{Sounding Speed}

The speed of the vessel used was affected by a lot of environmental factors such as, nature of seabed at some point, echo sounder pulse, water turbulence other moving vessels using the route, nature of creek. Howbeit, the vessels speed was between 0.5-5.3 knots $\left(2.727 \mathrm{~ms}^{-1}\right)$, which is a function of the acceleration and deceleration of the vessel by the operator. This speed is displayed on the Echo sounder, and was constantly monitored by the surveyor, to signal the boat operator when the vessel's speed is above limit.

\subsection{Results and Discussion}

The results of the various stages of data acquisition are as discuss below.

\subsection{Levelling Reduction}

Table 3.0 below shows the reduction process of the levelling data and the assessment of the accuracy of the data is thereafter discussed.

Table 2: Levelling Reduction

\begin{tabular}{|c|c|c|c|c|c|c|c|c|c|c|c|}
\hline \multicolumn{12}{|c|}{ SOUNDING ON WOJI RIVER } \\
\hline \multirow{2}{*}{\multicolumn{5}{|c|}{ GEOINFORMATICS UNIVERSITY OF UYO }} & \multirow{2}{*}{\multicolumn{4}{|c|}{ LEVELLING SHEET }} & \multirow{2}{*}{\multicolumn{3}{|c|}{ PAGE }} \\
\hline & & & & & & & & & JOB No.: & & \\
\hline \multicolumn{2}{|c|}{ SURVEYED BY } & \multicolumn{3}{|c|}{ Eyakndue Nsikakobong } & \multicolumn{4}{|c|}{ INSTRUMENT: } & \multicolumn{3}{|c|}{ JOB TITLE } \\
\hline \multicolumn{5}{|c|}{ CHECKED BY : Dr. A. U. Ekpa } & \multicolumn{4}{|l|}{ NO. } & \\
\hline \multicolumn{5}{|c|}{$: 06-05-2015$} & LOCATION & & \multicolumn{2}{|c|}{ Woji } & & & \multirow{5}{*}{$\begin{array}{l}\text { STAFF } \\
\text { STATION }\end{array}$} \\
\hline \multirow{4}{*}{$\begin{array}{l}\text { STAFF } \\
\text { STATION }\end{array}$} & \multirow{4}{*}{ DIST. } & \multirow{2}{*}{\multicolumn{3}{|c|}{ STAFF READINGS }} & \multicolumn{6}{|c|}{ REDUCTION } & \\
\hline & & & & & \multirow{3}{*}{$\begin{array}{c}\text { HEIGHT } \\
\text { OF } \\
\text { INSTR. }\end{array}$} & \multirow{3}{*}{ RISE } & \multirow{3}{*}{ FALL } & \multirow{3}{*}{$\begin{array}{l}\text { PROV. } \\
\text { HEIGHT }\end{array}$} & \multirow{3}{*}{ CORR. } & \multirow{2}{*}{\begin{tabular}{|l} 
FINAL HT. \\
*LLWS \\
*MSL \\
\end{tabular}} & \\
\hline & & \multirow[t]{2}{*}{ BACK } & \multirow[t]{2}{*}{ INTER } & \multirow[t]{2}{*}{ FORE } & & & & & & & \\
\hline & & & & & & & & & & *PROJECT & \\
\hline TOP & & 1.108 & & & & & & 5.952 & & 4.844 & \\
\hline C/P 1 & & 0.967 & & 3.732 & & & & 3.187 & & 2.220 & \\
\hline $\mathrm{W} / \mathrm{L}$ & & & 2.165 & & & & & & & 1.022 & $08: 20 \mathrm{Hrs}$ \\
\hline CP2 & & 3.283 & & 0.967 & & & & 5.503 & & 2.220 & \\
\hline TOP & & & & 0.658 & & & & & & 4.845 & \\
\hline
\end{tabular}

The accuracy of the levelling reduction reveals as follows:

Summation of Back Sight $=5.358 \mathrm{~m}$

Summation of Fore Sight $=5.357 \mathrm{~m}$

Error $=($ Summation of Back Sight $)-($ Summation of Fore Sight $)$

Error $=(5.358-5.357) \mathrm{m}$

Error $=0.001 \mathrm{~m}$

OR

Error $=$ Last Reduce Level - First Reduce Level

Error $=(4.845-4.844) \mathrm{m}$

Error $=0.001 \mathrm{~m}$

For Third Order leveling operation, the accuracy is given as follows: 
Where: $\quad \mathrm{K}=$ total distance in Kilometer.

From the observation, $\mathrm{k}=1 \mathrm{~km}$

Therefore, accuracy $=20 \mathrm{~mm} \sqrt{ } 1= \pm 0.02 \mathrm{~m}$. Therefore, the measurement was within the allowable error

\subsection{Tidal Data Reduction}

Levelling from GPS 01 to the water level surface was taken to it at 08:20 hours, simultaneously as tide gauge readings was observed. This was to relate the tide chart datum to the existing vertical control. Thus, at $08: 20 \mathrm{Hrs}$, the level to water was observed to be $3.732 \mathrm{~m}$, while the tide reading was taken to be $2.165 \mathrm{~m}$ (see Figure 8 ). Therefore, the relationship between these two readings were then deduced.

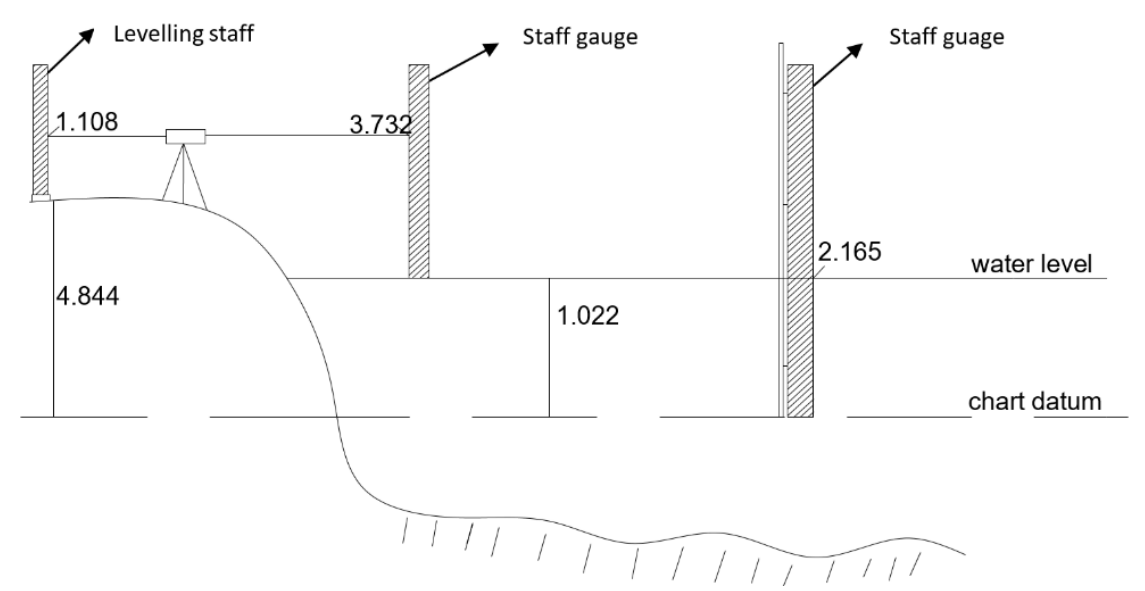

Figure 8: Reduction of tidal data to Chart Datum

However, these tidal values were not used for the reduction, since the field result obtained did not show the highest and lowest water level for the period which the sounding operation lasted.

From Total Tide, the values for 01-May-2015, for Mean Low Water (MLW) and Mean High Water (MHW) were extracted for time series from (06:00 hrs.-12:00 hrs.) as follows:

$$
\begin{gathered}
\text { Mean Low Water }(\mathrm{MLW})=1.000 \mathrm{~m} \\
\text { Mean High water }(\mathrm{MHW})=1.450 \mathrm{~m} \\
\text { The predicted Mean Water Level }(\mathrm{MWL})=\frac{1.000 \mathrm{~m}+1.450 \mathrm{~m}}{2} \\
\text { Thus, the Mean Water Level }(\mathrm{MWL})=\mathbf{1 . 2 2 5} \mathbf{~ m} .
\end{gathered}
$$

Similarly, results of the pre- and post-sounding calibration checks are as shown in Tables 3 and 4 respectively.

Table 3: Pre- Sounding Calibration Check

\begin{tabular}{|c|c|c|c|c|c|}
\hline $\begin{array}{c}\text { Calibration Time } \\
(\mathbf{2 4 H r s})\end{array}$ & $\begin{array}{c}\text { Bar Check } \\
\text { Depth }\end{array}$ & \multicolumn{2}{|c|}{$\begin{array}{c}\text { Echo Sounder Depth Reading } \\
\text { (2 pings) }\end{array}$} & $\begin{array}{c}\text { Mean } \\
\text { Depth } \\
(\mathbf{m})\end{array}$ & Remarks \\
\hline $\mathbf{0 8 : 2 0}$ Hrs & $1 \mathrm{~m}$ & $1.15 \mathrm{~m}$ & $1.03 \mathrm{~m}$ & 1.09 & Ok \\
\hline $\mathbf{0 8 : 2 0} \mathrm{Hrs}$ & $2 \mathrm{~m}$ & $2.10 \mathrm{~m}$ & $2.05 \mathrm{~m}$ & 2.08 & Ok \\
\hline
\end{tabular}


Table 4: Post- Sounding Calibration Check

\begin{tabular}{|c|c|c|c|c|c|}
\hline $\begin{array}{c}\text { Calibration Time } \\
\mathbf{( 2 4 H r s )}\end{array}$ & $\begin{array}{c}\text { Bar Check } \\
\text { Depth }\end{array}$ & \multicolumn{2}{|c|}{$\begin{array}{c}\text { Echo Sounder Depth } \\
\text { Reading (2 pings) } \\
\mathbf{1}^{\text {st }} \text { Reading }\end{array}$} & $\begin{array}{c}\text { 2. } \\
\mathbf{2}^{\text {nd }} \text { Reading } \\
\text { Depth } \\
(\mathbf{m})\end{array}$ & Remarks \\
\hline $\mathbf{0 9 4 0 ~ H r s}$ & $2 \mathrm{~m}$ & $2.10 \mathrm{~m}$ & $2.05 \mathrm{~m}$ & 2.08 & Ok \\
\hline $\mathbf{0 9 4 0} \mathrm{Hrs}$ & $1 \mathrm{~m}$ & $1.13 \mathrm{~m}$ & $1.03 \mathrm{~m}$ & 1.08 & Ok \\
\hline
\end{tabular}

\subsection{Sounded Depths Reduction}

This implies the calculation of the reduced level of sounded depth reference to the adopted datum. The reference datum adopted was Mean Water Level $(1.225 \mathrm{~m})$. Reduced data is shown in Appendix I. The diagram for the reduction is shown in Figure 9.

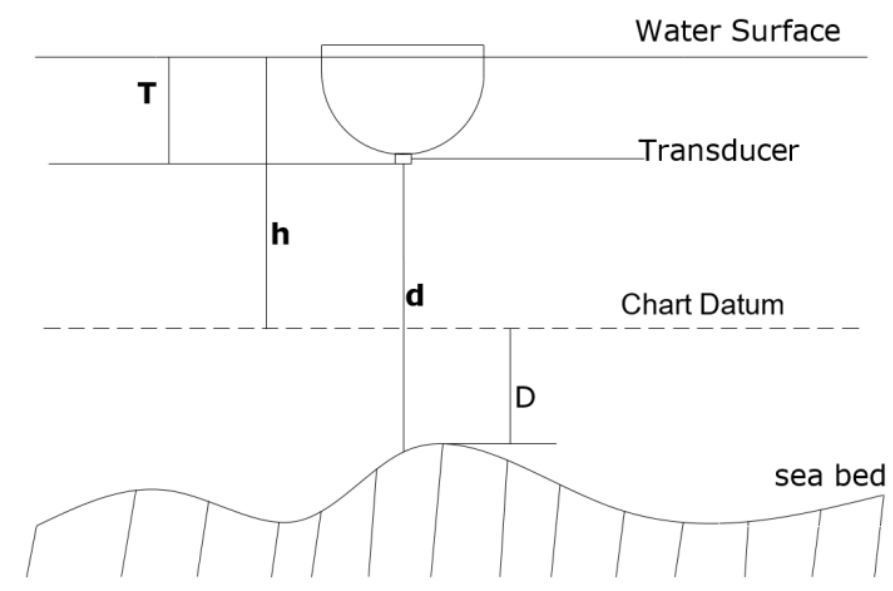

Figure 9: Reduction of Sounded Depth (Source: Ojinnaka, 2007)

From the Figure 9,

Where:

$$
\mathrm{D}=\mathrm{d}+\mathrm{T}-\mathrm{h}
$$

$\mathrm{D}=$ depth of chart datum above sea bed

$\mathrm{d}=$ Sounded depth

$\mathrm{T}=$ depth of transducer below water surface

$\mathrm{h}=$ height of water surface above chart datum

Furthermore, the height relating the seabed topography to the established benchmark (above the water surface) was also deduced to obtain the contour and profile information of the seabed.

\subsection{Assessment of the Sounding Accuracy}

Sounded depth accuracy can be calculated according to IHO standard (Wells, 2002). This was categorised as Order 1 Survey because it is limited to areas with depth less than 100m,

These surveys are intended for harbour surveys, approach channels to harbours, recommended tracks, inland navigation channels, and coast areas of high commercial traffic density, where under keel clearance is less critical and the geophysical properties of the sea floor are less hazardous to vessels (Gourlay and Cray, 2009). For this survey, the following data are standards at $95 \%$ confidence level for an Order 1 bathymetric survey.

$$
\begin{aligned}
& a=0.5 \mathrm{~m} \\
& b=0.013 \mathrm{~m}
\end{aligned}
$$




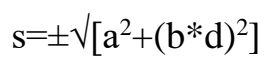

where, $\quad \mathrm{a}=$ constant depth error, i.e. the sum of all constant errors

$b^{*} d=$ depth dependent error, i.e. the sum of all depth dependent errors

$\mathrm{b}=$ factors of depth dependent error

$\mathrm{d}=$ depth.

$\mathrm{s}=$ bathymetric uncertainty.

To calculate the error limits for depth accuracy the corresponding values of ' $a$ ' and ' $b$ ' are introduced into the formula above. For this work, the max depth was $12 \mathrm{~m}$, which was used as ' $\mathrm{d}$ ', $\mathrm{a}$ and $\mathrm{b}$ are constants. Introducing the above into the formula would yield $\mathrm{S}= \pm 0.5237 \mathrm{~m}$.

From the provided values for uncertainty for a bathymetric survey (s) of an Order 1 Survey, which is $\leq 1.39 \mathrm{~m}$ (Ojinnaka, 2007), it is obvious that the depth accuracy was within IHO specification.

\subsection{Presentation and Discussion}

Bathymetric data can be presented in a number of formats and styles, depending on the intended purposes. For this study, the bathymetric chart of part of Woji River was plotted using AutoCAD Civil 3D 2016, due to its flexibility.

The data in $X, Y, Z$, and $T$ were downloaded from the Midas Echo Sounder via a copyright software known as Surveylog, saved in Microsoft Excel 2010, in T,X,Y,Z format, and processed using Civil3D software. The products of this exercise were the bathymetry chart and plan profile the Woji River (Figure 10) and the contour map of the seabed topography as shown in Figure 11. From these figures, the best channel routes for vessels navigation can conveniently be ascertained to ensure safety against loss of lives and properties.

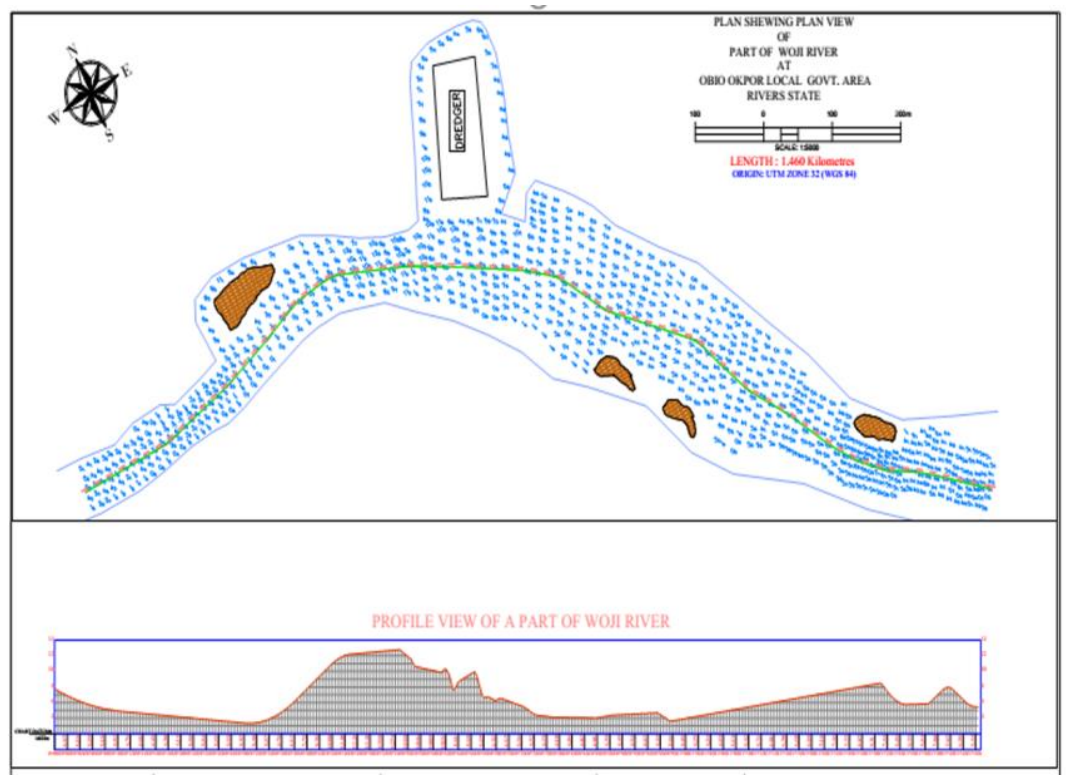

Figure 10: Bathymetry Chart and Profile of Part of Woji River 




Figure 11: Contour Map of Part of Woji River

\subsubsection{Digital Terrain Model/Contouring/Profiling}

To create a Digital Terrain Model and contour map of the creek, Golden Surfer Software application was used to interpolate the irregularly spaced sounding data into a regularly spaced grid surface using a Kringing Algorithm and a blank function was introduced to trim-off extrapolated areas. The interval employed was $1 \mathrm{~m}$. The grid American Standard Code for Information Interchange (ASCII) file obtained was used for creating a digital terrain model.

A Profiled seabed is one where the shape is specified by a 2D profile in a particular direction. Profiling was done in Civil 3D 2016, by creating an alignment along the river's centreline. The essence is to obtain a longitudinal profile view of the seabed, which could be used to estimate the level of cut and fill in the case of exploitation for land reclamation (see Figure 12).

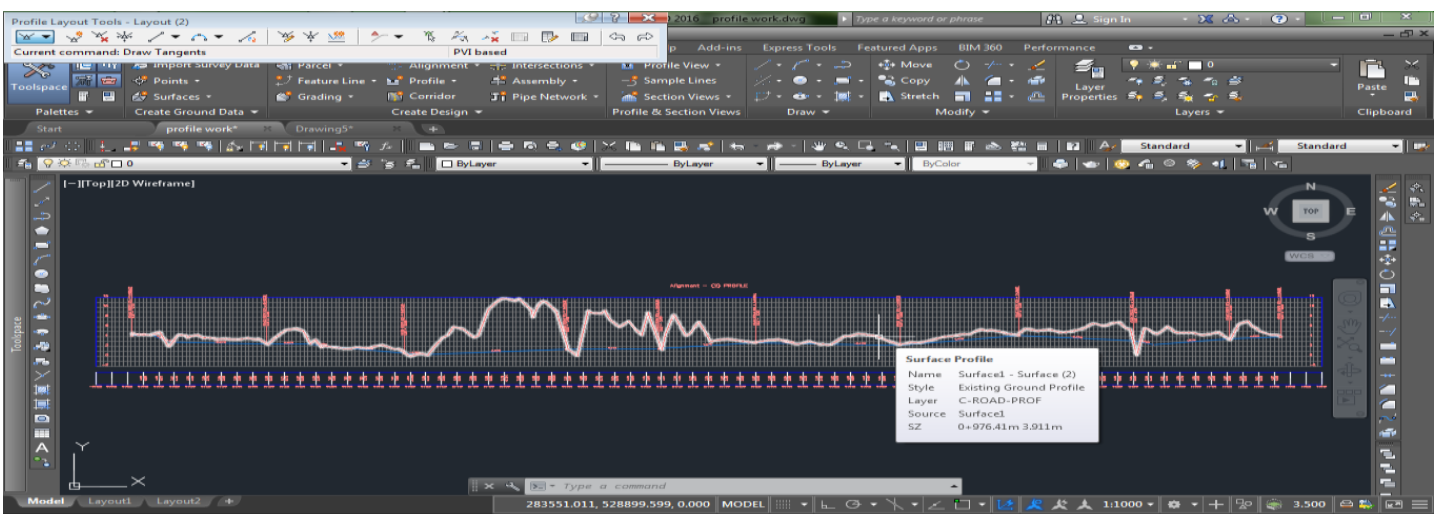

Figure 12: Screenshot of the seabed profile showing the level of cut and fill for land reclamation

Furthermore, a 3-Dimensional scene was created from the DEM (Digital Elevation Model) created in ArcMap 10.3. This DEM was exported as a raster data and symbology adjustment and rendering were applied to this raster data to produce a 3D scene of the surveyed river bed (Figure 13). 


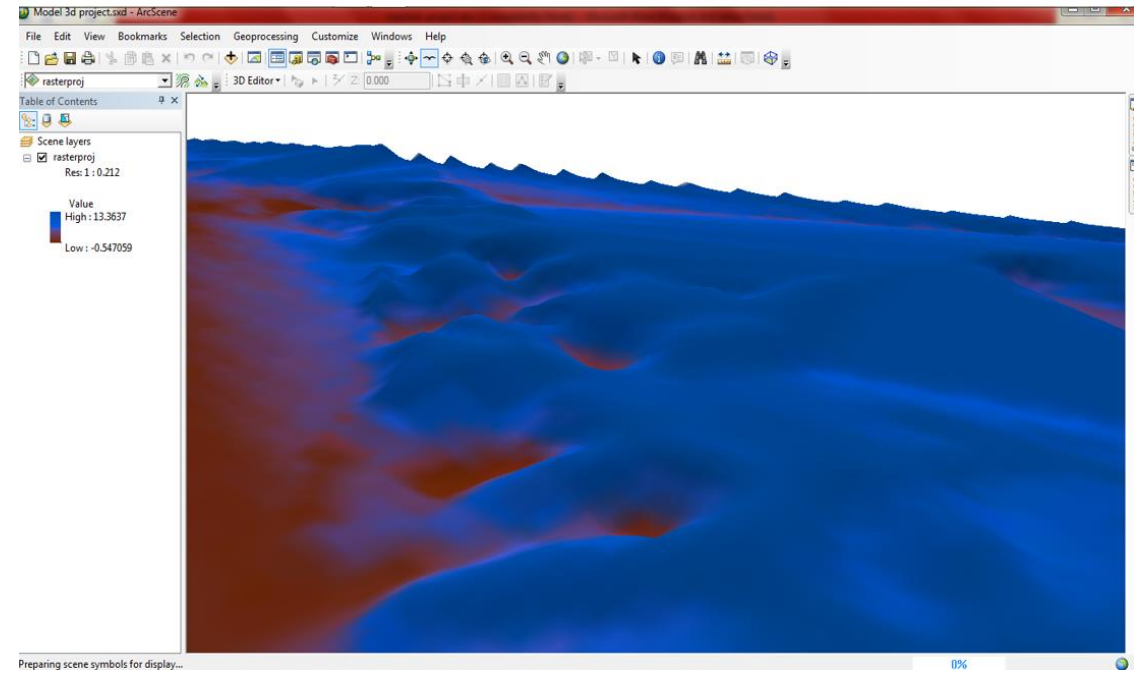

Figure 13: 3-Dimensional veiw of the surveyed river bed

(Showing water as blue and sandy region as dark brown)

In addition, there was an inclusion of a flow analysis using Beaufort Wind Analyst to determine the direction of wind flow, current and tidal stream effect on the nearby banks. From the vectorized flow arrows, it was noticed that there was continued sedimentation towards the northward side of the river bank. As a result, the sand in this region was fairly weak to hold any solid object placed on it. More so, dirt was also noticed on this part of the region due to the effect of the tidal stream movement (see Figure $14)$.

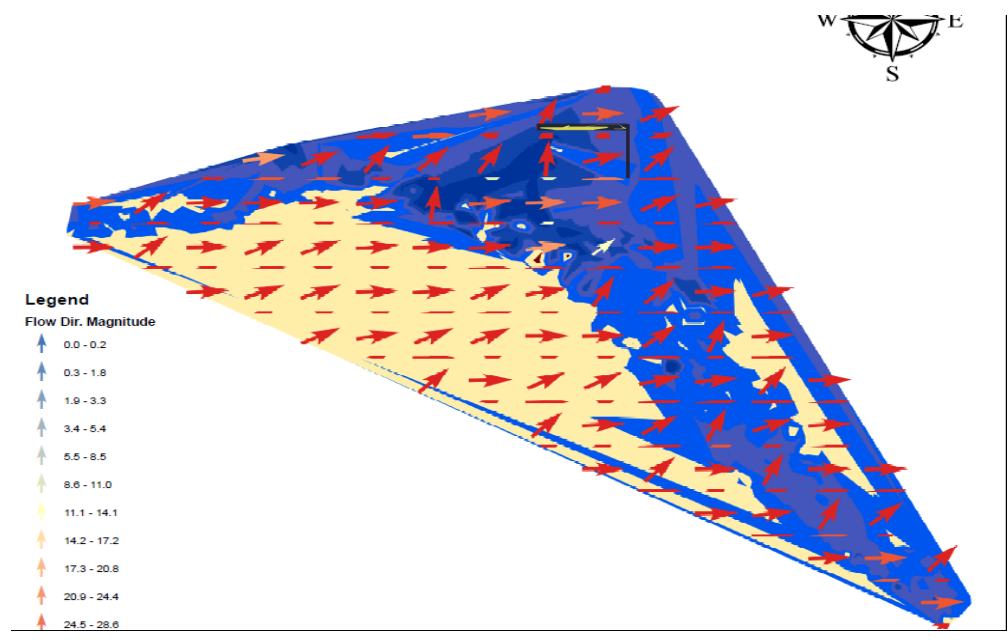

Figure 14: Vector Arrows showing direction of tidal streams and current on the river

\subsection{Conclusion and Recommendations}

\subsection{Conclusion}

The use of Midas GPS Dual Frequency Echosounder in bathymetry depth measurement was able to give adequate seabed information of the section of Woji River. The results presented indicate that there are very useful to hydrographers, sailors, fishermen and other professionals. The seabed information presented could effectively be useful in improving safety of vessels' navigation within this section of the river, as well as, areas that can be marked as danger to navigation. The flow pattern (tidal stream) of the river has also revealed areas that are susceptible to sedimentation that should be avoided by vessels. On the summary, the results of this study, show that efficient bathymetry survey of the entire Woji River would effectively enhance safety of navigation and subsequently prevent loss of lives and properties. 


\subsection{Recommendations}

- Based on the study carried out it is advisable that engineering facilities raised in this region should be structurally secured to prevent washed off by the coastal erosion. Proper sand filling should also be done, and setback lines should be strictly adhered to, in order to prevent structural damage, loss of live and property. Mud (sinking sand) such as those found along the shoreline should be avoided and marked as danger.

- Though single beam acquisition instrument was employed, it is strongly recommended that Sonar (multi beams) equipment be employed in order to ensure effective coverage of the seabed. This will ensure that narrow ridges, shoals and wrecks are adequately captured. However, the points data collated could be integrated into a well-designed database, and used online to assist sailors, and other sea users. All these would go a long way in ensuring navigational safety, time conservation and quick completion of onshore task such as, barge movement, refueling, positioning etc.

- Since this study is concentrated only on a section of the river, there is need to carry out extensive study to cover the entire river in order to derive maximum economic benefits associated with it. These include increase fishing produce, improve revenue to the government, creation of employment opportunities for the un-employed and restive youths in the region (Niger Delta), etc.

\section{References}

Breman, T. A. (2010). Bathymetry-the art and science of seafloor modeling for modern application. California: ESRI.

Gourlay, T.P. and Cray, W.G., (2009). Ship under-keel clearance monitoring using RTK GPS. Proc. Coasts and Ports, Wellington, New Zealand.

Ojinnaka, O. C., (2007). Principles of hydrographic surveying - form sextant to satellite. El' Demak Publishers, Enugu, Nigeria.

Panigrahi, N. (2014). Computing in geographic information systems. Boca Raton: CRC Press.

Spratt, J. D. (1989). The distribution and density of eelgrass, zostera marina, in Tomales Bay. In California fish and game. Carlifornia press (pp. 204-212).

Wells, D. E. (2002). IHO S44 Standard for Hydrographic Surveys and Variety of Requirement for BAthymetric Data. Monaco: International Hydrographic Bureau. 
Appendix I

Sample Data of Depth Reduction

\begin{tabular}{|c|c|c|c|c|c|}
\hline Time & Eastings & Northings & $\begin{array}{c}\text { Sounded } \\
\text { Depth }\end{array}$ & Corr. & $\begin{array}{c}\text { Reduced } \\
\text { Depth }\end{array}$ \\
\hline $08: 25: 25$ & 283811.124 & 532315.882 & 3.89 & 1.225 & 2.665 \\
\hline $08: 25: 30$ & 283823.325 & 532312.364 & 4.82 & 1.225 & 3.595 \\
\hline $08: 25: 35$ & 283844.319 & 532309.638 & 4.13 & 1.225 & 2.905 \\
\hline $08: 25: 40$ & 283891.515 & 532296.200 & 3.33 & 1.225 & 2.105 \\
\hline $08: 25: 45$ & 283918.734 & 532309.041 & 2.92 & 1.225 & 1.695 \\
\hline $08: 25: 50$ & 283942.048 & 532270.369 & 3.06 & 1.225 & 1.835 \\
\hline $08: 25: 55$ & 283956.329 & 532308.607 & 2.84 & 1.225 & 1.615 \\
\hline $08: 26: 00$ & 283980.402 & 532315.235 & 2.86 & 1.225 & 1.635 \\
\hline $08: 26: 05$ & 283993.159 & 532316.892 & 4.08 & 1.225 & 2.855 \\
\hline $08: 26: 10$ & 284017.299 & 532317.937 & 5.48 & 1.225 & 4.255 \\
\hline $08: 26: 15$ & 284037.160 & 532329.530 & 4.56 & 1.225 & 3.335 \\
\hline $08: 26: 20$ & 284063.462 & 532340.390 & 6.53 & 1.225 & 5.305 \\
\hline $08: 26: 25$ & 284145.813 & 532369.487 & 8.78 & 1.225 & 7.555 \\
\hline $08: 26: 30$ & 284162.325 & 532377.868 & 7.73 & 1.225 & 6.505 \\
\hline $08: 26: 35$ & 284215.983 & 532323.617 & 4.32 & 1.225 & 3.095 \\
\hline $08: 26: 40$ & 284232.347 & 532368.456 & 4.35 & 1.225 & 3.125 \\
\hline $08: 26: 45$ & 284281.015 & 532298.581 & 5.42 & 1.225 & 4.195 \\
\hline $08: 26: 50$ & 284247.400 & 532371.010 & 6.8 & 1.225 & 5.575 \\
\hline $08: 26: 55$ & 284264.948 & 532360.400 & 8.96 & 1.225 & 7.735 \\
\hline $08: 27: 00$ & 284266.981 & 532348.071 & 10.3 & 1.225 & 9.075 \\
\hline $08: 27: 05$ & 284266.126 & 532316.563 & 12.8 & 1.225 & 11.575 \\
\hline $08: 27: 10$ & 284283.898 & 532321.341 & 12.7 & 1.225 & 11.475 \\
\hline $08: 27: 15$ & 284286.965 & 532346.169 & 11.8 & 1.225 & 10.575 \\
\hline $08: 27: 20$ & 284300.090 & 532340.070 & 11.1 & 1.225 & 9.875 \\
\hline $08: 27: 25$ & 284316.882 & 532324.926 & 11.1 & 1.225 & 9.875 \\
\hline $08: 27: 30$ & 284317.171 & 532334.400 & 11.6 & 1.225 & 10.375 \\
\hline $08: 27: 35$ & 284328.650 & 532331.030 & 9.66 & 1.225 & 8.435 \\
\hline $08: 27: 40$ & 284347.792 & 532322.605 & 11.3 & 1.225 & 10.075 \\
\hline $08: 27: 45$ & 284344.885 & 532255.636 & 11.6 & 1.225 & 10.375 \\
\hline $08: 27: 50$ & 284370.355 & 532326.550 & 12.1 & 1.225 & 10.875 \\
\hline $08: 27: 55$ & 284382.190 & 532312.849 & 11.3 & 1.225 & 10.075 \\
\hline 08:28:00 & 284385.284 & 532322.003 & 12.3 & 1.225 & 11.075 \\
\hline $08: 28: 05$ & 284375.404 & 532343.449 & 9.46 & 1.225 & 8.235 \\
\hline $08: 28: 10$ & 284414.994 & 532307.654 & 5.63 & 1.225 & 4.405 \\
\hline $08: 28: 15$ & 284369.724 & 532335.026 & 6.16 & 1.225 & 4.935 \\
\hline $08: 28: 20$ & 284425.299 & 532300.889 & 6.74 & 1.225 & 5.515 \\
\hline $08: 28: 25$ & 284438.040 & 532296.099 & 8.34 & 1.225 & 7.115 \\
\hline $08: 28: 30$ & 284448.166 & 532290.396 & 7.1 & 1.225 & 5.875 \\
\hline $08: 28: 35$ & 284468.250 & 532278.030 & 6 & 1.225 & 4.775 \\
\hline $08: 28: 40$ & 284471.332 & 532244.733 & 5.54 & 1.225 & 4.315 \\
\hline $08: 28: 45$ & 284482.833 & 532265.806 & 6.08 & 1.225 & 4.855 \\
\hline $08: 28: 50$ & 284471.769 & 532209.409 & 7.73 & 1.225 & 6.505 \\
\hline $08: 28: 55$ & 284504.043 & 532253.180 & 8.31 & 1.225 & 7.085 \\
\hline 08:29:00 & 284534.509 & 532276.145 & 8.23 & 1.225 & 7.005 \\
\hline $08: 29: 05$ & 284514.700 & 532241.118 & 8.14 & 1.225 & 6.915 \\
\hline $08: 29: 10$ & 284528.167 & 532268.148 & 7.78 & 1.225 & 6.555 \\
\hline $08: 29: 15$ & 284529.566 & 532231.391 & 7.59 & 1.225 & 6.365 \\
\hline $08: 29: 20$ & 284525.081 & 532222.184 & 6.71 & 1.225 & 5.485 \\
\hline $08: 29: 25$ & 284542.018 & 532214.894 & 5.97 & 1.225 & 4.745 \\
\hline
\end{tabular}

